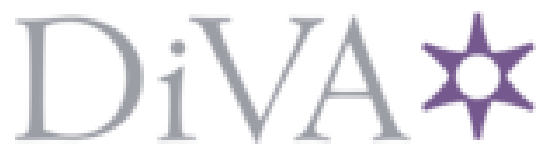

http://www.diva-portal.org

This is the published version of a paper presented at 13th Toulon-Verona Coference,University of Coimbra, Portugal.

Citation for the original published paper:

Ljungblom, M., Hallencreutz, J., Isaksson, r. (2010)

Knowledge management challenges

In:

N.B. When citing this work, cite the original published paper.

Permanent link to this version:

http://urn.kb.se/resolve?urn=urn:nbn:se:uu:diva-348869 


\section{Knowledge management challenges}

Mia Ljungblom - MSc Pedagogy, University Lecturer, Gotland University mia.ljungblom@hgo.se

Jacob Hallencreutz, PhD-student and Licentiate of Technology, Luleå University of

Technology jacob.hallencreutz@implement.se

Raine Isaksson - PhD, Senior University Lecturer, Gotland University -

raine.isaksson@hgo.se

\section{Abstract}

Knowledge management could be seen as identifying knowledge that needs to be managed, followed by the process of acquiring, refining, storing and using the identified knowledge. Good knowledge management could be seen as the foundation of a learning organisation. With increasing competition and a quicker pace of change it becomes more and more important to be a quick learner. In this challenge universities are no exception. A good knowledge management system assures that all relevant knowledge is being used in all important activities. This is particularly important in large change projects. A process based system view could be used to describe how knowledge management is visualised. Especially visualising knowledge management on organisational change competence could be a challenge.

In this case study we analyse the implementation of a new approach in education - Liberal Education, and to what extent existing change knowledge was used. The findings are categorised and related to drivers for good change management and to organisational learning disabilities in a quality management context.

The purpose of the study is to understand learning disabilities and how to describe them. The results should constitute a starting point for later work to overcome these disabilities.

\section{Keywords}

Organisational Change; Knowledge Management; Learning organisation; System processes; Learning disabilities.

\section{Introduction}

Survival of most organisations depends on their ability to implement change (Hallencreutz, 2009). But not only change is important, it is also stated that the key to organisational success is in the organisation's capacity to change and to develop new knowledge. The organisation needs to be one that is continuously learning (Alvesson \& Sveningsson, 2007). Granberg and Ohlsson (2009) state that the learning organisation is "the organisation that creates good conditions for the co-workers learning and take care of and utilize this in the organisations aspiration to influence and adapt to the surrounding world with the purpose high effectiveness" (Granberg and Ohlsson, 2009:51). To lead and control this learning process you need knowledge management (Granberg \& Ohlsson, 2009).

Effective and efficient processes for knowledge management could be seen as prerequisites for becoming a learning organisation. Knowledge management has many definitions. In simple terms it could be defined as: "Knowledge management is the systematic, continuous process of collecting, filtering, storing, accessing, applying and refining of information and knowledge for attaining higher levels of competence". The purpose of knowledge management is to identify knowledge which is critical for the organisation, find it and/or 
create it, bring it into the organisation, store it and see that it is used to add value. Even if the fully learning organisation is a utopia there is a point of being a quicker learner than competition. Senge (1990) argues that the only competitive advantage in the future will be to learn more quickly than competition. It is safe to assume that the pace of change will become even quicker in the future and that one important area of knowledge will be change management. How is change competence identified, stored and used?

Organisations are seemingly in a more or less constant state of change with new requirements, new products, increasing competition and ongoing reorganisation. Generally organisations in change could be seen to constitute interesting objects for study and it should be possible to learn from both successes and mistakes. One interesting question is to what extent change experiences are used for internal learning and how these are made part of a knowledge management system.

\section{Methodology}

The methodology is based on action research and storytelling. Action research is a form of research that requires collaboration between the researcher and the object researched (Bell, 2000). Bell (2000) claims that there are a lot of different definitions of action research but that most are always usable when the purpose is to improve the area. Action research is seen as research methodology that aims to contribute both to practical concerns and to scientific knowledge (Rapoport, 1970). Bell (2000) emphasizes action research as an approach suited to any organisation where the purpose is to provide understanding and to develop. Bell (2000) also claims that an important property in action research is that the task does not end after finishing the project.

Storytelling is a narrative form where you can see how people understand their surrounding world and how they create a meaning. Through stories the human being creates her or his identity and reality. Storytelling is to convert abstract information to become understandable, meaningful and memorable (Dennisdotter \& Axenbrant, 2008). A narrative study, like storytelling, is about how stories are created and collected and then related to other stories (Czarniawska, 2004).

We review a major change project consisting of the introduction of a new pedagogical profile involving all campus education. We study how required knowledge for successful change has been used and how experiences have been recorded. The required knowledge has been identified by a study of change management literature. This study is based on one in depth case study of a university in Sweden. The change project is believed to be a typical example of organisational change. Another reason for studying this project has been the good availability of data over an extended period of time.

The introduction of Liberal Education (LE) is described differently by different groups. The introduction can be grouped into several different stories of the same reality. The change can also be described in project management terms. The different perceptions of what has changed are contrasted with a project management model and Kotter's change model (Kotter, 1996).

The main empirical data used consists of student's essays about the implementation of LE. These essays were produced on a course in change management where the LE introduction was studied as an example of planned change. Five different reports were produced by seven students all of whom used some 50-100 hours each for the work. The third year students are following a cross functional education preparing them to become change specialists. Based on 
this information and our review of the work done we consider this part of the empirical information highly relevant. We have also interviewed key persons in the change project. The university webpage and additional documents have been studied to see how LE and the introduction have been presented and how the result has been understood. Two of the authors have also to some extent participated in the LE process. These insights are also used to complement the "Analytical story", see below. This presents some problems of objectivity. We are conscious of this. To reduce the bias in the assessment of the stories we have let the final assessment to our third author who has not been part of the LE discussions.

\section{Theoretical background}

There are two underlying beliefs about organisational change. The first is that organisational change can be planned and managed by a set of sequential steps, and the second belief is that change is an organic process which cannot be managed (Hallencreutz, 2009).

\section{Theories about change}

There are several theories and models of change and the change process. One frequently used theory on how to manage planned change is described by Kotter (1996), who proposed an eight-step process, see Table 1.

\section{Table 1. Kotter's eight-step process (1996)}

1. Establishing a sense of urgency

2. Creating the guiding coalition

3. Developing a vision and a strategy

4. Communicating the change vision

5. Empowering broad-based action in the organization.

6. Generating short-term wins

7. Consolidating gains and producing more change

8. Anchoring new approaches in the culture

Kotter (1996) argues that for change to be successful it needs to follow this eight-step process and that it is necessary to be patient and let the change take the time it needs.

Planned change could also be described as a project. There are several project models. We have used one based on Tonnquist (2006). Tonnquist (2006) uses a model described in four fazes - pre-study, planning, realization and conclusion. Tonnquist (2006) also provides assessment criteria for a successful project that can be used to identify strengths and weaknesses in the studied change initiative, see Table 3. There has been some debate of whether the change was a project or not. Even if not officially labelled as a project it can be analysed as one (Tonnquist, 2006).

Change could also be seen as organic and something which cannot be planned and do not occur in steps. Organic change could be seen more like a sense-making approach where people in a specific social system (an organization for example) create for themselves the systems of meaning of their world (Hallencreutz, 2009).

\section{Central elements in change}

Jacobsen (2005) argues that an organisation can be seen as a system built of central elements - formal elements and informal elements. Formal elements are those that describe how the organisation is structured, how strategies are chosen, how responsibilities look like, objectives decided etc. The informal elements are described as the culture in the organisation - values, 
behavioural rules (Jacobsen, 2005). These two perspectives of an organisation are illustrated in Figure 1.

$$
\begin{gathered}
\text { Technical and } \\
\text { institutional }
\end{gathered}
$$

ENVIRONMENTS

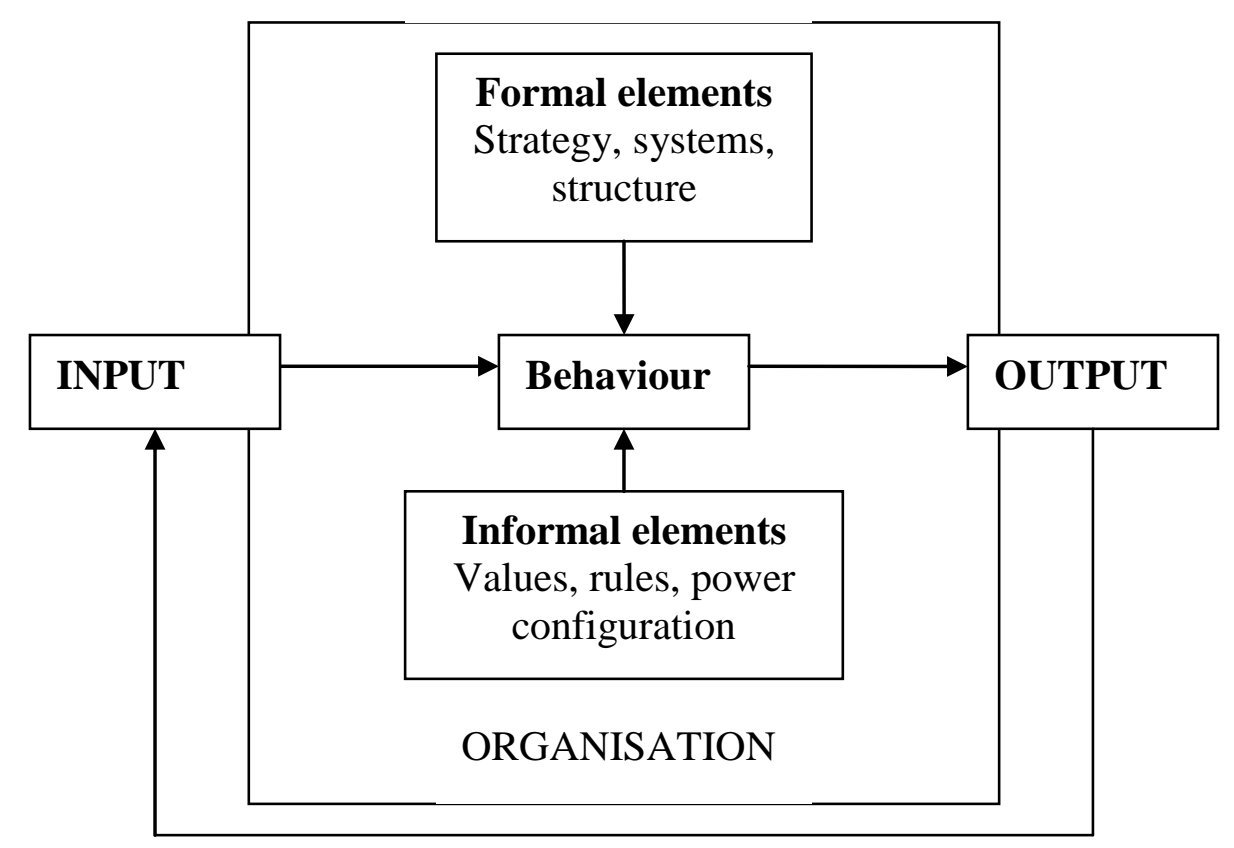

Figure 1: Jacobsen and Thorsvik's model of the link between central elements in an organisation, (Jacobsen, 2005:93).

\section{Theories about the learning organisation}

A learning organisation is learning by itself. It increases its knowledge and develops through a constant in-house dialogue (Mayo \& Lank, 1994). Mayo and Lank (1994) define a learning organisation as: "A learning organisation uses all the intelligence, knowledge and experience, which is available for the organisation with the purpose of always progressing in a way which is beneficial for all its stakeholders" (Mayo \& Lank, 1994:8).

Many have companies have organisational learning disabilities Senge (1990:17). The traditional way to organise, to describe work tasks and to reason could create substantial learning disabilities. The first step to start changing this is to recognize these disabilities. There are seven different disabilities (Senge, 1990:17-25)

1. I am my position. Not seeing the big picture and not having a sense for wholeness and only seeing your own work situation.

2. The enemy is out there. When something goes wrong, the blame is someone's fault instead of understanding how the system works.

3. The illusion of taking charge. Wanting to be proactive, but doing it based on faulty analysis due to lack of system understanding.

4. The fixation on events. Focus on happenings and short term decisions instead of seeing the system and the long time requirements

5. The parable of the boiled frog. Not recognising threats that are slowly growing. 
6. The delusion of learning from experience. Not learning from experiences because we have not seen the consequences of many of our most important decisions (e.g. due to a time lag between decision and consequence)

7. The myth of the management team. Leading team that is afraid of losing face. The leading team avoids things that can make them look bad.

Kotter (1996) has categorized eight different types of errors that organizations do that can sabotage the change processes. The first error is that people in the organisation don't care about what is happening. The second error is that the organisation takes it too easy when creating the leading team - they do not see the importance of skills needed. Engagement and a strong team are important prerequisites, but need to be followed by a good vision. The third error is underestimating the power of a vision. The fourth error is under-communicating the vision. Error number five is about obstacles - when the organisation and/or the leading team permit obstacles to block the new vision. Real change takes time and for gaining new energy and power to continue the organisation needs short-term wins. The sixth error is failing to create the wins. The seventh error is that the organisation declares victory too soon. The last and eighth error is neglecting to anchor changes firmly in the organisational culture (Kotter, 1996).

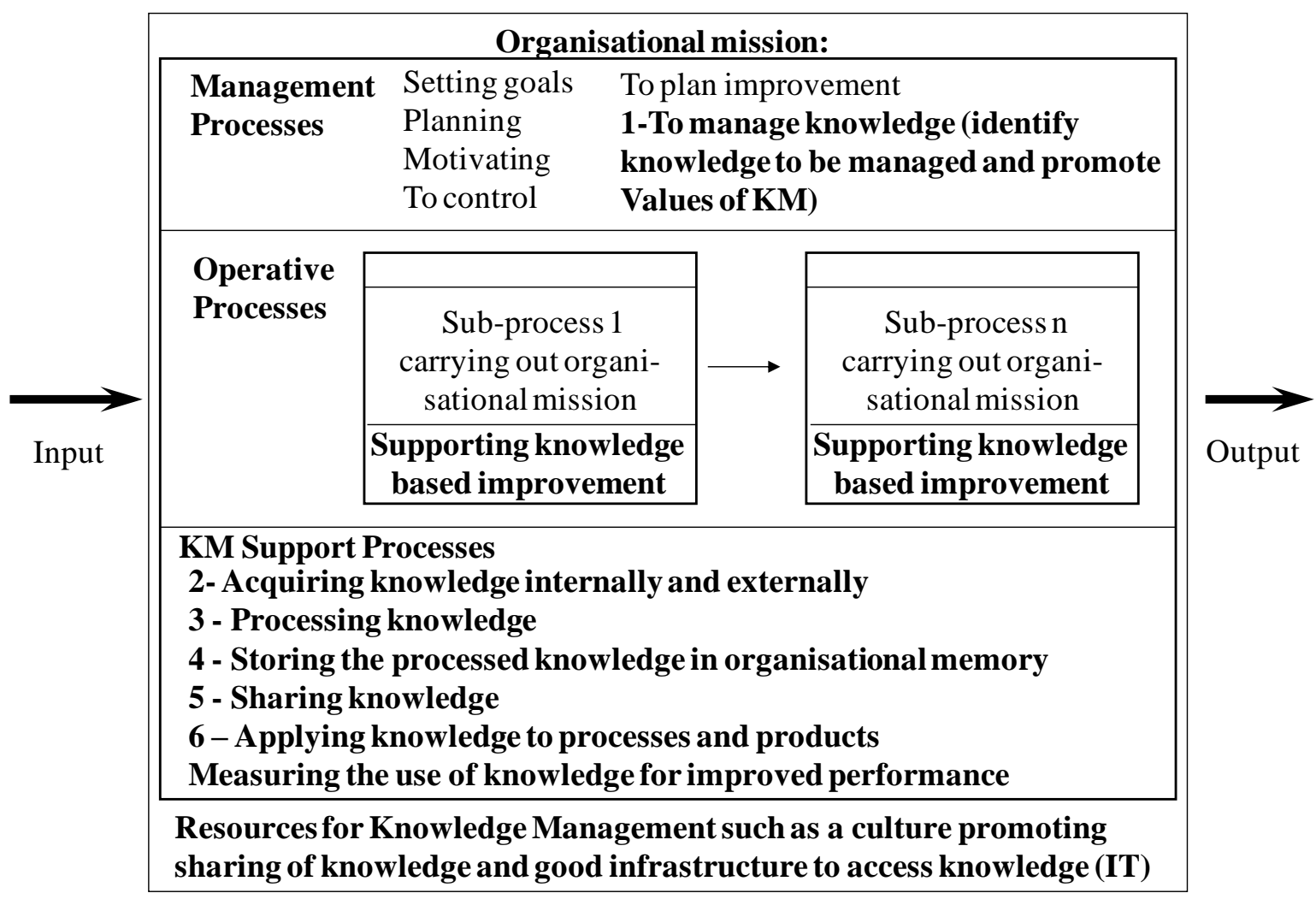

Figure 2: A process based system model with focus on how Knowledge Management could be included in a process based system model (Isaksson \& Trönndal, 2005).

Argyris (1990) argues that there is a basic strategy for human beings to avoid embarrassment or treat through bypassing and then covering up the bypass. He also claims that when many individuals do use these actions they become organisational norms - Organisational defensive routines. Defensive routines create inconsistencies and dilemmas and the organisation does not learn of their own errors. A learning process often involves processes where things go wrong and it is crucial to be able to study failures in order to learn. Argyris (1990) claims that when something goes wrong, a lot of people look for another strategy that will work without 
questioning basic assumptions or ideas. This is single-loop learning. An alternative response is to question why something goes wrong and also to question our assumptions, the learning substance and how the learning process looks like. This is double-loop learning. Single-loop learning seems to be present when goals, values, frameworks and strategies are taken for granted. Double-loop learning, in contrast, involves questioning the role of the framing and learning systems which underlie actual goals and strategies (Agyris, 1990).

Knowledge Management (KM) could be seen as a prerequisite for the learning organisation. So, in order to learn as quickly as possible the knowledge that needs to be managed needs to be identified, collected, stored, developed and used. Isaksson \& Trönndal (2005) describe KM as a process that should be anchored both in the management processes and as a support process for continuously providing the needed information. This can be described as part of a process based system model, see Figure 2. The system model is presented with special focus on Knowledge Management (KM). Apart from the recorded KM processes, there would normally be a number of other support processes (Isaksson, 2006).

$\mathrm{KM}$ is an abstract concept and in many organisations the critical knowledge to manage might not have been identified. When speaking about knowledge of how change is carried out, whether continuous and incremental (kaizen) or sporadic and breakthrough (kaikaku), it could be assumed that this is even more abstract and probably less managed than that of the core competence.

\section{The introduction of liberal education}

To describe the introduction process and the concept of Liberal Education (LE) we use the concept of story telling (Dennisdotter \& Axenbrant, 2008). The change can be described using different stories told by different stakeholders. We have identified the following five stories: The official, the leading team, the employee, the student and the analytical story. The summary interpretation and analysis of these stories forms the main contribution of this paper.

\section{Official story}

The official description is based on an analysis of data from the official website including steering documents. This information tells us that LE is a part of the University and is well implemented. Documents claim that the University is working with developing an educational model based on a LE concept. The document which describes the teacher's role at the University says that the engagement to every student are set for shaping the education based on the student's expectations, needs and dreams. As a teacher you should also be familiar with the university's activities as wholeness. At the web site (verified June 1, 2010) you can read that you (as a student) at the University can design your own program on campus. The University has chosen this education model to give the student the best conditions for entering working life. We can also read about how student experiences are part of LE.

The interpretation based on these documents is that LE has been introduced and is working.

\section{Leading team story}

For this story we have interviewed three persons in the leading team for the LE project. Their answers are interpreted and summarised. LE has, compared to earlier education, a holistic approach focused to see the whole student and to prepare the student for working life. This indicates needs for a broad range of competencies outside of the main subject. The biggest difference is that this approach requires more collaboration between different topics. LE provides more options, flexibility, practice and individual solutions. The interviewees cannot in detail describe what type of change LE constitutes of, but one says that it is a concretisation 
of something that we already have done at the University. Another one makes the point that we must remember that the University was in a bad situation in the middle of 2000 with negative capital. "We had to do something - to find a new strategy". However, the new strategy is still in making. The project started after a study in 2006 with a gradual introduction rather than a planned effort. It is described as a "bottom up process". Totally more than 100 co-workers have participated in dialogues/seminars about LE. The change was according to one of the interviewed in the beginning (2007) operated like a project. In 2008 there were structural changes in the education at campus and there where also a first pilot version of LE involving two programmes. After evaluations the whole university campus education was involved in autumn 2009 and LE is planned to be totally implemented in 2012. Nowadays LE is lead by a steering group. One of the interviewed key persons was not aware of any goals or plans. The leading team experiences a lack of urgency among teachers - "many teachers did not understand how critical the university situation was and some teachers were opposing this change". Things mentioned on the positive side were such as most employees having the right attitude, good collaboration, competent teachers and a willingness to make this work. The future challenge is experienced to be to change the steering model so that it works together with LE. "The evaluations' tells us that we must be better in communication and in gaining approval of why LE is necessary for us". To the question - is it a "positive" or" negative" change, they answered: "Hard to tell - but a change is necessary. We must strengthen our brand to survive and everybody in the university world is interested in our change project. It is easy to be self critical and we could have done things better - like communication". "But it's also very hard - we have invited people to different meetings, but none have come or very few - then they tell us that we haven't informed them enough". A lot of things have also worked well - like the pilot try in 2008. Learning outcomes are that there is generally a need to introduce better planning and evaluation processes and do systematic analyses".

The interpretation based on the leading team story is that LE has been partly introduced; it is a bottom-up process and is going to work fully in 2012.

\section{Employee story}

This story was created by analysing a special survey looking at student and employee opinions of LE after the educational year 2009. In the special survey we can read about the experiences from the staff - both teachers and administrators. In this story we have also used interviews of employees carried out by students in the earlier mentioned change management course.

There are different stories from teachers depending on if they are distance teachers or not. The teachers involved in LE (not distance) marked approval in a range between 4 and 6 on a ten grade scale. There is a positive peek in increased self-esteem from the new teacher's role and a negative peek when it comes to information and knowledge of the choosing-differentcourses process. In the open questions there are comments such as that they miss a document defining LE, and that there is too much focus on the structure in the information about LE. When it comes to distance teachers we can see that the interviewed teachers are more negative and feel that the distance courses have been neglected. A teacher who earlier has worked with LE feels that only a small part of what should be LE has been introduced at the University and points out that important parts have been lost.

In the survey the administrators' average marks are around 5 of the ten grade scale, with a positive peek in the statement that: "it is really good with no lessons during one day of the week". In the open questions there are comments such as that more participation and 
information is needed and that there have been troubles with clashing courses and the course choice process.

Simultaneously, when LE already should have been introduced there is a group of teachers working to find an explanation of what LE really is. This work was started during 2009 and has still been going on during 2010. The group proposes four important components of LE: Guidance (tutoring), teaching forms, collaboration and the view of the student's development. What should differentiate the university with LE work is a conscious, systematic and bottomup process that impregnates all areas.

The interpretation is that not all teachers feel involved, especially those working with distance courses. Some are of the opinion that LE practises already are done and that no more changes are needed. Many still struggle with understanding what LE is. Based on this it could be assumed that things might not have changed that much, but that a full LE introduction still has a long way to go.

\section{Student story}

This story was also created by analysing the special survey used in the employee story. In this story we have also used interviews of students participating in LE, done by students in the change management course, asking for other student's opinions.

\section{Students \\ 2008 dots \\ 2009 marks}

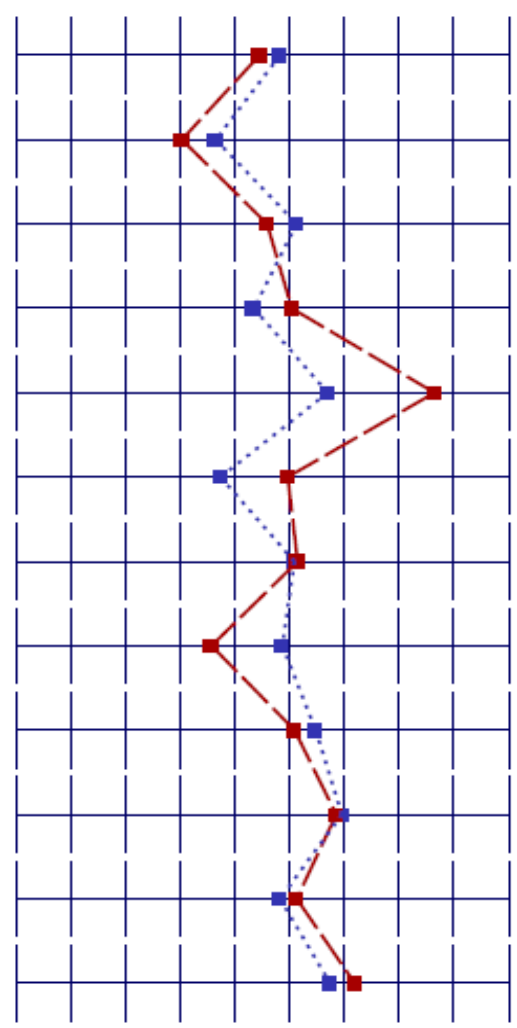

The information 2009, about the education, has been adequate

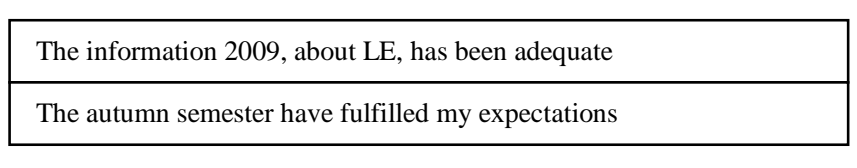

It has been good to study parallel half-time courses

It has been good to have non scheduled Wednesdays

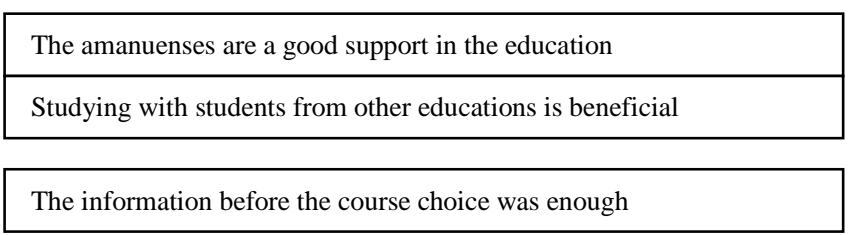

How did the choice work out for you?

The information about the library has been adequate

Do you use the resources of the library?

The university premises fulfil my needs and wishes

Figure 3: A comparison between student experiences in LE 2008 and 2009.

When we look at the latest evaluation results we can read that the students generally are not very satisfied with the information around the concept LE - some of them do not even seem to know what it is about. The students rather prefer to study full-time courses instead of the half-time courses being the norm within LE. They also indicate that teachers in the two parallel courses need to be more synchronised. Most of the students think that they have enough with tutor time, but some of the students ask for more lectures. The students are very 
pleased with the teachers' engagement. All students who participated in the evaluation think that it is really good with no lessons one day a week.

In Figure 3 an evaluation from students who participated in the early LE concept 2008 and how experiences from these students (blue line with dots in the figure 3) compare with that of the students from 2009 (red line in figure 3). The comparison shows that with some issues (half of the items) the students from 2008 gave higher rates than the students 2009. The left side in the figure (3) stands for lower rating and the right side stands for higher rating.

Summary of the student story shows that the students are not fully satisfied with the LE concept, and some of them do not even know what LE is about. The results from Figure 3, with some lower scores from the later evaluation of 2009, suggest that there could be some problems with the organisational process of continuous improvement and learning. The general interpretation of the survey results is that the expected results of the LE-introduction in the form of increased student satisfaction have not yet been realised. This could be because the LE is still not fully implemented or because the version of LE introduced is not as successful as expected.

\section{Analytical story}

This story is based on a summary of an analysis of LE introduction done by students in the mentioned change management course. The student results have additionally been compiled and analysed by the teachers. Methods used are Kotter's (1996) eight-step change process and Tonnquist (2006) assessment criteria for successful projects.

\section{Establishing a sense of urgency}

No sense of urgency or a false sense of urgency. A false sense of urgency is defined as urgency without direction (Kotter, 2008). That is, employees knew that something needed to be done, but it was not clear what. LE was presented as the only or last option and was accepted as such. Some departments were of the opinion that they already worked according to LE. With this assumption there will be no urgency for change. Also, the LE concept would only apply to campus courses even if more than $60 \%$ of courses were provided on distance. This indicates that urgency among teachers with few or no campus courses would have been limited.

\section{Creating the guiding coalition}

The responsibility - and role divisions seems to have been unclear and spontaneous. However, good competences were available as well as a mix of both sceptics and enthusiasts in the leading team. Here, sceptics are based on Kotter (2008) defined as critical persons that can be convinced with good arguments. Having these aboard guarantees some level of critical scrutiny. Change of rectors in the middle of the introduction created difficulties (mid 2009).

\section{Developing a vision and a strategy}

The students talk about a gradually rising solution. Initially there was a high level of ambition with goals for LE in the operational plan. However, an officially defined vision for LE is missing and it is also unclear to whom LE applies.

\section{Communicating the change vision}

It seems obvious that everybody did not get the required information about LE and the change project.

\section{Empowering broad-based action in the organization.}


Routines for tutoring are compiled and an LE-education has been started involving a major part of the organisation. However, distance teachers are not involved, which excludes an important group. The extra resources sought for the LE introduction have not been granted which means that there have been limited funds for extra activities. There has been a reorganisation starting autumn 2009 and going into 2010 which has absorbed time and energy and thereby indirectly reduced focus on LE.

\section{Generating short-term wins}

There have been some short-term wins - first pilot year was done, pedagogical development is in progress and tutoring is available. However, on the side of results there are so far no clear examples such as more satisfied students, higher throughput or better economy.

\section{Consolidating gains and producing more change}

There is so far not much to consolidate. LE has been started officially. LE is frequently mentioned both at meetings and in discussions with external stakeholders.

\section{Anchoring new approaches in the culture}

This is still too early to analyse properly.

Table 2. Results based on Kotter's eight-step process as assessed by the change management students.

\begin{tabular}{|l|c|c|c|c|c|}
\hline Kotters eight-step & Student 1 & Student 2 & Student 3 & $\begin{array}{c}\text { Student 4- } \\
\mathbf{5}\end{array}$ & $\begin{array}{c}\text { Student 6- } \\
\mathbf{7}\end{array}$ \\
\hline $\begin{array}{l}\text { Establishing a sense of } \\
\text { urgency }\end{array}$ & No or false & No or false & Yes & - & Some \\
\hline $\begin{array}{l}\text { Creating the guiding } \\
\text { coalition }\end{array}$ & Low & Medium & Low & Low & Medium \\
\hline $\begin{array}{l}\text { Developing a vision and a } \\
\text { strategy }\end{array}$ & No vision & No vision & No vision & No vision & No vision \\
\hline $\begin{array}{l}\text { Communicating the change } \\
\text { vision }\end{array}$ & Low & Low & Low & Low & Low \\
\hline $\begin{array}{l}\text { Empowering broad-based } \\
\text { action in the organization }\end{array}$ & Low & Low & Low & Low & Low \\
\hline Generating short-term wins & Low & Low & Low & - & Low \\
\hline $\begin{array}{l}\text { Consolidating gains and } \\
\text { producing more change }\end{array}$ & Low & Low & Low & - & Low \\
\hline $\begin{array}{l}\text { Anchoring new approaches } \\
\text { in the culture }\end{array}$ & Low & Low & Low & Low & Low \\
\hline
\end{tabular}

The assessment in Table 2 shows that all students perceive that there is no vision.

\section{Tonnqvist}

The students have also used the Tonnquist (2006) assessment criteria to identify strengths and weaknesses in the studied change initiative, see Table 3.

The summary of the work was presented to rector, pro-rector and one more key-person in the leading team of LE. Most of the present persons had also been interviewed of the students. The presentation was appreciated but seemingly considered to be too negative. The presentation did not lead to any apparent changes in any practises related to LE or to change management as a consequence of the presentation.

The summary of the analytical story is that as a change initiative, based on the assessments used, the change work carried out was far from optimal. The two analyses highlight the risk of 
that actual change could have been limited. The lack of response to the results presented could indicate some learning barriers.

Table 3. Evaluation form for the anticipated success of a project, produced by Boston consulting group, (Tonnquist, 2008:280) completed with results from the change management course reports including interviews of key persons, teachers and administrative personnel.

\begin{tabular}{|c|c|c|}
\hline Variable & Question & Judgement \\
\hline $\begin{array}{l}\text { Duration } \\
\text { (D) }\end{array}$ & $\begin{array}{l}\text { - How often is the project reviewed? } \\
\text { The estimation is that the project reviews are done } \\
\text { more seldom than eight months which gives an } \\
\text { average of } 4 .\end{array}$ & $\begin{array}{l}1 \text { more often than } 2 \text { months } \\
2 \text { Between } 2-4 \text { months } \\
3 \text { Between } 3-4 \text { months } \\
4 \text { More seldom that } 8 \text { months }\end{array}$ \\
\hline $\begin{array}{l}\text { Integrity } \\
\text { Performance } \\
\text { (I) }\end{array}$ & $\begin{array}{l}\text { - Has the change leader adequate skills? } \\
\text { - Ire the project group motivated and able? } \\
\text { Average } 4\end{array}$ & $\begin{array}{l}1 \text { if YES in all questions } \\
2 \text { or } 3 \text { if the answers are separated } \\
4 \text { if NO in all questions }\end{array}$ \\
\hline $\begin{array}{l}\text { Management } \\
\text { Commitment } \\
\text { (C1) }\end{array}$ & $\begin{array}{l}\text { - Does the leading team often communicate } \\
\text { the purpose with the project? } \\
\text { - Is the message convincing? } \\
\text { - Is the message the same from all the } \\
\text { leading team? } \\
\text { - Has the leading team allocated enough } \\
\text { resources? } \\
\text { To Management Commitment }(\text { Cl) the students } \\
\text { answered yes to that all in the leading team have the } \\
\text { same message, but no to the other questions- } \\
\text { Average 3. }\end{array}$ & $\begin{array}{l}1 \text { if the leading team shows in words } \\
\text { and act the urgency of the change. } \\
2 \text { or } 3 \text { if the leading team are neutral } \\
\text { to the change. } \\
4 \text { if the leading team shows its } \\
\text { repulsion to the change. }\end{array}$ \\
\hline $\begin{array}{l}\text { Local-level } \\
\text { Commitment } \\
\text { (C2) }\end{array}$ & $\begin{array}{l}\text { Do the most exposed to the change } \\
\text { understand the cause and do they see it as } \\
\text { urgent? } \\
\text { Are they enthusiastic and do the support } \\
\text { the change? } \\
\text { To Local-level commitment (C2) - Average } 3 \text {. }\end{array}$ & $\begin{array}{l}1 \text { if the co-workers are urgent. } \\
2 \text { if the co-workers just are positive } \\
3 \text { or } 4 \text { if the co-workers strongly } \\
\text { disagree the change }\end{array}$ \\
\hline $\begin{array}{l}\text { Effort } \\
\text { (E) }\end{array}$ & $\begin{array}{l}\text { - How much are employees required to } \\
\text { increase their efforts? } \\
\text { Do the extra workload in the top of an } \\
\text { already tough working situation? } \\
\text { Have people already opposed the increased } \\
\text { workload? } \\
\text { Students estimated that the working load increased } \\
\text { with 10-20 percent-Average } 2 \text {. }\end{array}$ & $\begin{array}{l}1 \text { if it needs less than } 10 \% \text { increase } \\
2 \text { if its } 10-20 \% \\
3 \text { if its } 20-40 \% \\
4 \text { if the workload increases with more } \\
\text { than } 40 \%\end{array}$ \\
\hline \multicolumn{3}{|c|}{ Value of change $=\mathrm{D}+2 \mathrm{I}+2 \mathrm{C} 1+\mathrm{C} 2+\mathrm{E}$} \\
\hline \multicolumn{3}{|c|}{$\begin{array}{ll}\text { Between } 7 \text { and } 14 & \text { The project will succeed. } \\
\text { Between } 14 \text { and } 17 & \text { Unsure if The project will succeed. } \\
\text { Over } 17 & \text { High risk than the project fails. } \\
\text { Result based on the formula above } 4+8+6+6+2=26, \text { which indicates a high risk that the project fails }\end{array}$} \\
\hline
\end{tabular}

\section{Analysis of results}

All information is reviewed and related to theories described.

\section{Summary of the five stories}

If we start to analyse the extent of change we can see that the stories present a different result of how far the implementation of LE has gone - from little to full implementation. In Figure 4 a qualitative assessment. The extent of LE introduction based on official documents is that LE has been introduced and is working well. The leading team's interpretation is more moderated 
and indicates that LE has been partly introduced and is going to work full time in 2012. The leading team story also tells us that LE is a bottom-up process. The Teacher's story indicates that not all teachers feel involved, especially those working with distance courses. Many still struggle with understanding what LE is and the same picture is presented in student's story. What is not understood is hard to implement, which indicates that the level of change could have been limited.

\section{Total}

implementation of LE

No LE at all

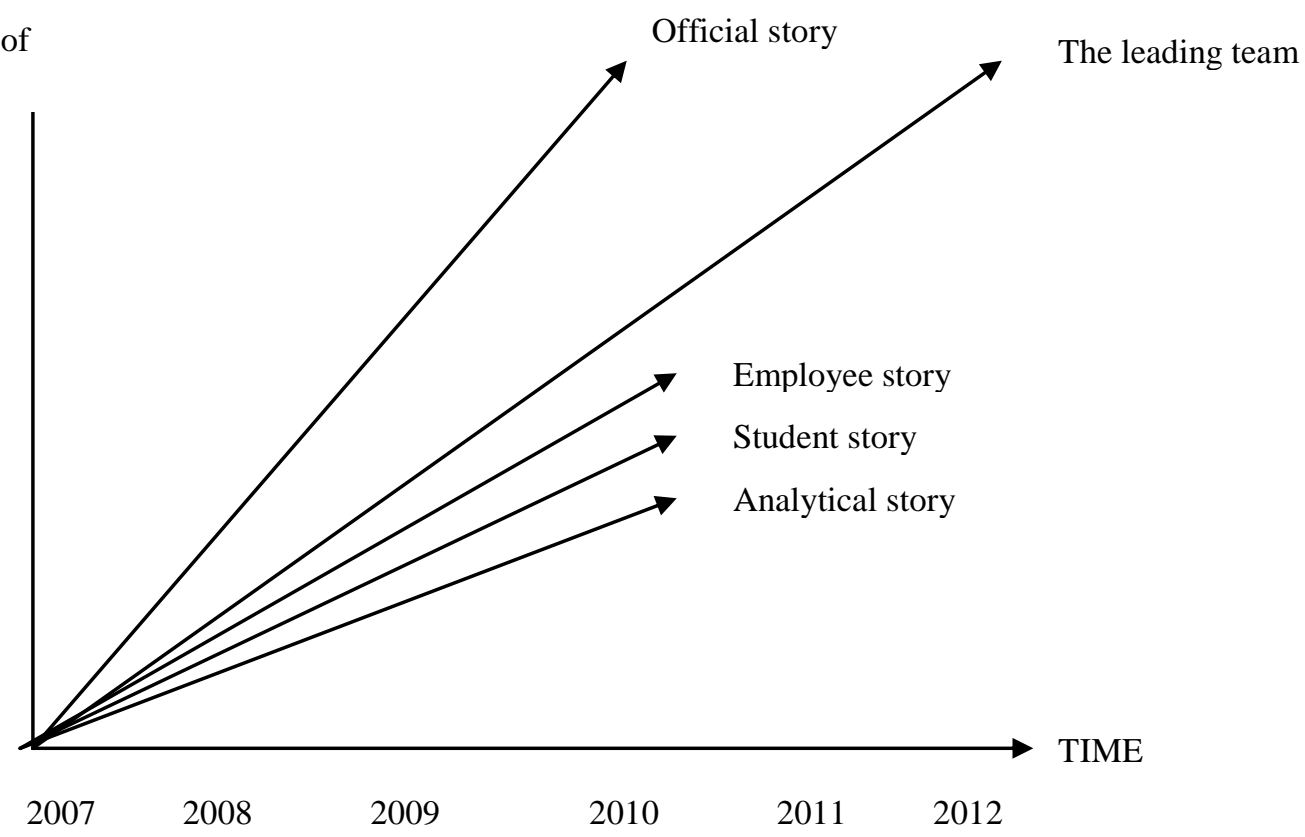

Figure 4: Assessment of the level of implementation over time based on the different stories.

Reality is always perceived differently but in this case the differences have to be considered exceptionally large. If the organisation would want to know how much change has taken place this could be found out. For example teachers could be asked to indicate what they do differently now compared to earlier.

How successful the introduced LE concept is could be measured based on student perceptions. The summary of the student story shows that they are not fully satisfied with the LE concept. At least there does not seem to be any considerable improvement. It is unclear to what extent economic performance and new student interest has been affected. This could possibly be explained with the fact that the extent of introduction is still limited.

Concerning the use of change competence the summary of the analytical story based on Kotter (1996) and Tonnquist (2008) indicates that common change knowledge was not applied. There is no indication that this fact has been registered as a learning experience so that forthcoming change projects can be handled differently. The special survey shows that half of the questions to the students shown in figure 3 score lower 2009 than in 2008. This indicates problems with continuous improvement and organisational learning.

\section{Learning disabilities and organizational defense mechanisms}

The fact that the differences between the stories told are large, indicate that there are learning disabilities in the university. The logic for this is that would there not have been any barriers the differences would have been taken up at the official organisational level and sorted out. 
We are using Senge's (1990) seven learning disabilities and Kotter's (1996) eight errors for our analysis. Results based on Senge (1990):

1. I am my position. Not seeing the big picture with particular disregard of the dominating distance education

2. The enemy is out there. The explanation of: Communication has not worked because employees have not shown enough interest.

3. The illusion of taking charge. Nothing observed.

4. The fixation on events. Nothing observed.

5. The parable of the boiled frog. Teachers not understanding the changing requirements in the university world.

6. The delusion of learning from experience. Results from surveys 2008 and 2009 indicate limited learning. Another issue is that there does not seem to be any measurement system in place that would make it possible to assess the success of LE introduction.

7. The myth of the management team. Not analysed.

Results based on Kotter (1996):

1. People in the organisation do not care about what's happening

To only involve campus courses and campus teachers has reduced the momentum

2. The organisation takes too easy when creating the leading team

This has been told by several stories.

3. Underestimating the power of a vision

No LE vision

4. Under-communicating the vision

Several stories tell us about the lack of information and communication

5. Permitting obstacle to block the change

Management has noted opposition, but has not dealt with it consequently

6. Failing to create the wins.

Wins are hard to visualise.

7. The organisation declares victory too soon.

The web documents tell us that LE is fully implemented, when it is not.

8. Neglecting to anchor changes firmly in the culture

Not analysed.

It is not clear what the reasons are for not using common knowledge on for example project management and change management? It could be related to the first step of Kotter's change process - lack of sense of urgency to do things differently from the way they always have been done.

\section{Structure for knowledge management}

A learning process often involves processes where things go wrong and it is crucial to be able to study failures in order to learn. Argyris (1990) claims that when something goes wrong, a lot of people look for another strategy that will work without questioning basic assumptions or ideas. This is single-loop learning - when goals, values, frameworks and strategies are taken for granted. Single -loop learning is what is described in Figure 5 from output back to input. But, the Figure 5 can also describe double-loop learning - to learn further and deeper. Questioning why something goes wrong and also to question our assumptions, the learning substance and how the learning process looks like which involves questioning the role of the frameworks and learning systems which underlie actual goals and strategies. 
Based on our findings the change process of implementation of LE concept does not live up to the presentation in Figure 5. The stories told indicate that the input has not been clear. There have been difficulties in formulating a clear vision, communicating this and creating sufficient engagement. Changes have mostly been limited to some formal elements such as instructions and organisational structure. The change in the informal elements such as behaviour, culture and motivation has been less noticeable. As long as employees are not motivated, engaged and involved in a change they will not change their behaviour. If this part is missing there will not be any change at all.

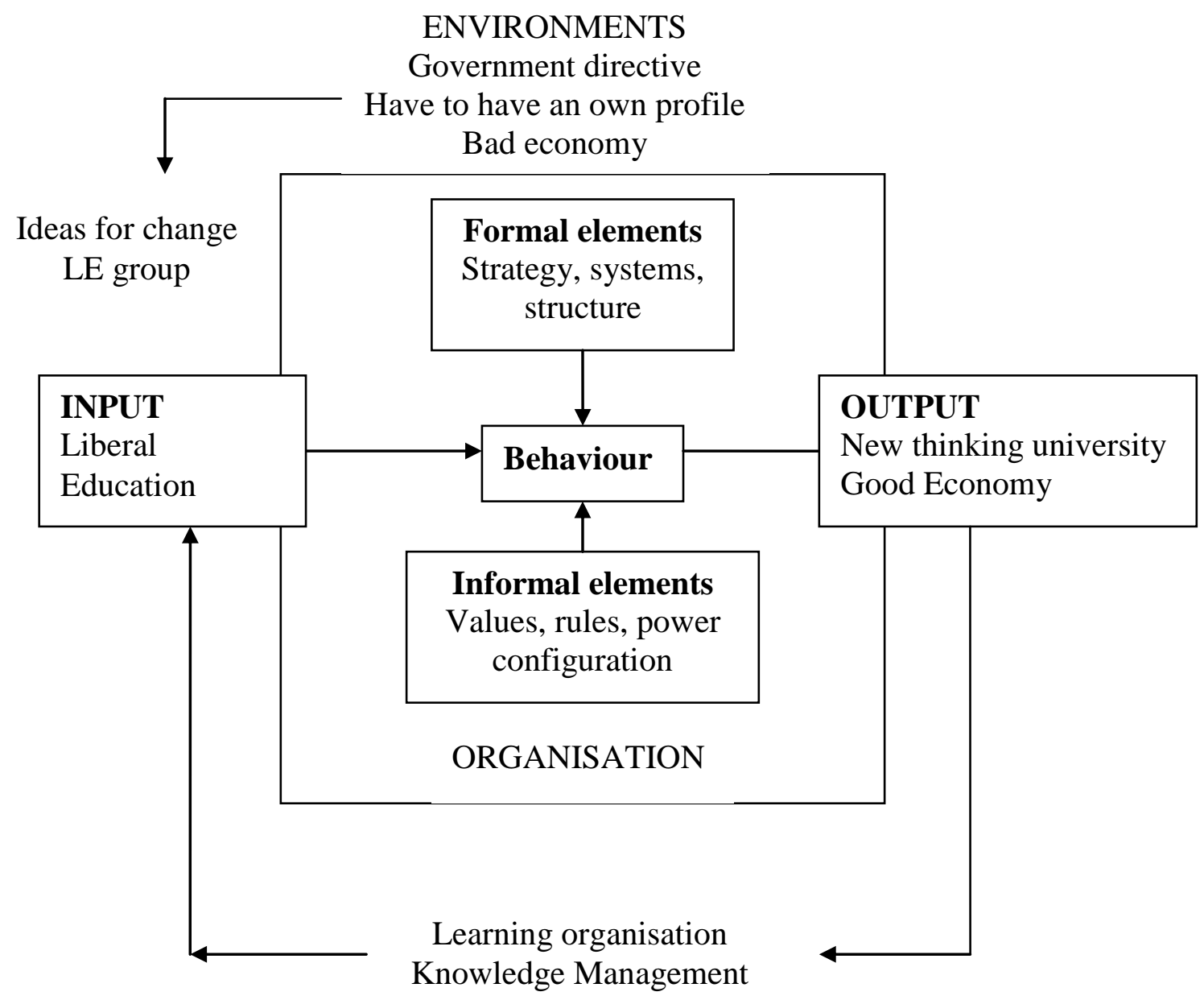

Figure 5: The LE implementation process - in the best of worlds - using the model of Jacobsen and Thorsvik (Jacobsen, 2005:93).

The most critical issue could be the non-existing loop of learning. It is not clear how much of change has taken place. Since this issue has not been officially addressed it is hard to see that there could have been any organisational learning. That is, there is a risk that there has not even been single loop learning since the problem has not been acknowledged. Single loop learning would mean that the apparent problems would surface officially and that actions would be taken to use basic change competence in future projects. Double loop learning would require that the question is posed why the problem occurred in the first place. What is the reason for not using common change competence which has been readily available, even internally in the organisation? Are there cultural issues, communication problems or does the organisation not share common values such as "letting everybody be committed" and "decisions based on facts"? Using the proposed structure for Knowledge Management in Figure 2 we make the following notes: 
1. To manage knowledge - no structure for this has been identified it seems that the concept is not an externalised part of the organisational competence and especially not in the field of change management

2. To acquire knowledge seems to be managed on an individual level only

3. Processing knowledge on change management is done by some teachers within their topic

4. Storing knowledge has an emerging approach in the form of DIVA which is an open data base for storing reports

5. Sharing knowledge with a particular view on change management does not appear to be structured, however, with the LE project feedback has been communicated to employees but mostly as raw data

6. Applying knowledge - no structured approach; New change initiatives seem to be managed as before with the addition of changes originating from individual learning experiences

\section{Conclusions and Discussion}

Generally it seems that Knowledge Management has not been identified as an area of management concern. More specifically Change Management competency is not handled as part of the organisational competence, which leads to limited learning from change initiatives. Most of the reasons for this can be explained by basic change theory and learning as described by Kotter (1996), Senge (1990) and Argyris (1990). The main problems have been the lack of a clear vision and objectives as well as clear plans. This makes communication a challenge that has not been mastered. Resistance to change has not been dealt with professionally.

Hallencreutz (2009) argues that there are a number of gaps in complex change processes. The LE project seems to demonstrate several of these. One gap is between planning and action in other words, between theory and practice. When change is implemented in an organisation most problems seem to occur during the implementation. Factors that Hallencreutz (2009) refer to are; "Poor management commitment combined with the lack of attention given to the human dynamics of change and a lack of knowledge of the underlying processes of change" (Hallencreutz, 2009:50). A problem that rises is that instead of action the organization turns into a state of "wait-and-see-if-this-change-is-for-real", were no change takes place. It can be argued that this breakdown is an effect of a failed planning process and that the implementation problems are to be found in earlier stages of the change process (Hallencreutz, 2009). Another gap that Hallencreutz (2009) has noticed is the gap between management and staff. Hallencreutz (2009) argues that persistent leadership, planning and communication seem to be general success factors. He also argues that the predominant reductionist approach to implement organizational change fails to account for the human dynamics of change: "The lack of contextual knowledge and ability to understand the human response to change results in change leaders who are unable to modify or overcome this gap...", further: "Managers' (dis-)ability to handle questions concerning how and why decisions are made, what alternatives are considered and how the change process impacts the employees affects the width of this gap" (Hallencreutz, 2009:52). The project seems to have started as a form of planned change, but has then turned into organic change (Hallencreutz, 2009).

The results should be seen as indicative and further fact finding is needed to confirm issues like the extent of change and the extent of learning. However, the change process can be described with some accuracy using well anchored literature. This makes us believe that the organisation has a good opportunity in improving knowledge management practises generally 
and knowledge management on change specifically. The key to this is management responsiveness and management interest in change.

\section{References}

Agyris, C. (1990). Overcoming organizational defenses. Allyn and Bacon, New York.

Alvesson, M. \& Sveningsson, S. (2007). Organisationer, ledning och processer.

Studentlitteratur (In Swedish), Lund.

Bell, J. (2000). Introduktion till Forskningsmetodik (In Swedish). Studentlitteratur, Lund.

Czarniawska, B (2004). Narratives in social science research. Sage, London.

Dennisdotter, E. \& Axenbrant, E. (2008) Storytelling - ett effektivt marknadsföringsgrepp (In Swedish). Liber, Malmö.

Granberg, O \& Ohlsson, J (2009). Från lärandets loopar till lärande organisationer. Studentlitteratur, Lund.

Hallencreutz, J. (2009) Models and Meaning. On management models and systems of meaning when implementing change (In Swedish). Universitettryckeriet, Luleå.

Isaksson, R. and Trönndal, M. (2005). Knowledge management with a process view. Proceedings of the 7th International Research Conference on Quality, Innovation and Knowledge Management - Application and Synthesis in the Global Economy, 16th - 18th February 2005, Kuala Lumpur, Malaysia.

Isaksson, R. (2006). Total Quality Management for Sustainable Development - process based system models. Business Process Management Journal, Vol. 12, 5, 632-645.

Jacobsen, D. I. (2005). Organisationsförändringar och förändringsledarskap (In Swedish). Studentlitteratur, Lund.

Kotter, J.P. (1996). Leading Change. Harvard Business School Press, Boston, Massachusetts.

Kotter, J.P. (2008). A sense of urgency. Harvard Business School Press, Boston, Massachusetts.

Mayo, A. \& Lank, E. (1994). Lärande i organisationen(In Swedish). Liber-Hermods, Malmö.

Rapoport, R. N. (1970). "Three Dilemmas in Action Research," Human Relations, 23(4), 499513.

Senge P. (1990). The Fifth Discipline. The Doubleday Publishing Group, New York.

Tonnquist, B. (2006). Projektledning (Project Management - in Swedish). Bonnier utbildning, Stockholm. 